\title{
Effect of Early Stabilization Exercise Focused on the Scapulothoracic Joint on the Recovery of Surgical Patients Due to Rotator Cuff Tear
}

\author{
Mo Beom Jeong', Dong Woo Lee² \\ ${ }^{1}$ Chung-Yeon Korean Medicine Hospital, Gwangju; ${ }^{2}$ Department of Physical Therapy, Honam University, Gwangju, Korea
}

\begin{abstract}
Purpose: This study examined the effects of early stabilization exercise focused on the scapulothoracic joint on the recovery of surgical patients due to rotator cuff tear.

Methods: The subjects were 30 patients divided randomly into two groups. Group I consisted of 15 patients who practiced shoulder joint stabilization exercises, including glenohumeral joint movement. Group II consisted of 15 patients who practiced scapulothoracic joint stabilization exercises, excluding glenohumeral joint movement. The duration of stabilization exercise was 30 minutes for one day, five days a week, and five weeks. To measure the dependent variables, the Disabilities of the Arm, Shoulder and Hand (DASH) questionnaire, range of motion (ROM), dynamometer of measured grip were used.

Results: The DASH, ROM, and grip power were compared. A significant difference was observed before the intervention in each group $(p<0.05)$, and there was no significant difference between group I and group II ( $p>0.05)$.

Conclusion: Both shoulder joint and scapulothoracic joint stabilization exercises were effective after the intervention compared to preintervention, but there was no difference between the two groups. Unlike many recent studies on the initiation of stabilization exercises, this study allays the concerns between the advantages of 'early exercise' and oppositions of previous studies about 'early exercise.' Nevertheless, further research regarding these subjects is needed.
\end{abstract}

Keywords: Early exercise, Shoulder stabilization exercise, Rotator cuff tear, Scapulothoracic joint, Glenohumeral joint

\section{서 론}

인체의 관절 중에 가장 높은 자유도를 가지는 관절이 어깨관절이다. ${ }^{1}$ 따라서 사용범위가 넓어 자주 사용되기 때문에 자주 손상을 입는 다. ${ }^{2}$ 자주 손상되는 어깨 질환 중 가장 흔한 유형이 돌림근띠 파열이 며, ${ }^{3} 50$ 세 이상인 경우 전층 돌림근띠 파열의 유병률은 $20-25 \%$ 이며 나 이가 들수록 증가한다. 돌림근띠 손상으로 인한 보존적 치료방법에 는 통증 완화를 위한 약물요법, 물리치료, 일상생활의 개선 등이 있고 보존적 치료에도 불구하고 4-6개월 이상 증상의 호전이 없이 통증이 계속 유발된다면 수술적 치료를 실시한다. ${ }^{5}$ 돌림근띠의 봉합 방법이 최근 관절경 기기 및 기술의 향상으로 인하여 전통적인 개방적 봉합 술로부터 관절경 어깨뼈봉우리 성형술 및 감압술에 이은 소절개 봉 합술 그리고 봉합까지 관절경으로 시행하는 방법으로 발전되고 있

Received Dec 31, 2019 Revised Feb 2, 2020

Accepted Feb 5, 2020

Corresponding author Mo Beom Jeong

E-mail mobeom_j@daum.net
다. ${ }^{6}$ 또한 재활이 중요한 문제로 부각되면서 수술적 치료의 성공여부 에 결정적인 역할로 인식된다. 관절의 강직을 초래 할 수 있고 조직의 위축과 약화, 관절가동성의 부족 등의 문제점들을 가진 전통적인 개 방적 봉합술이 관절경 도입으로 인해 수술적 치료의 성공여부로 인 식된 재활 프로토콜로써 의료기관에서 개발되고 있다. ${ }^{7}$

돌림근띠 수술 후 재활치료는 다른 스포츠 재활치료 프로그램과 유사하게 3 단계 내지는 4-5단계의 시기적 단계로 나눌 수 있으나 각 시기적 단계의 정확한 기간 및 재활치료 방법은 질환별 그리고 시행 기관별 그리고 수술의사 마다 조금씩 차이가 있다. 전통적으로 조기 운동'은 돌림근띠 봉합술 이후부터를 말하며, '지연 운동'은 4-6주(또 는 6-8주) 동안 팔걸이로 완벽하게 고정 이후 운동을 시행하는 것을 말한다. 조기 운동의 장점으로 수술 이후 관절가동범위의 확보와수 술 후 강직, 근육 위축 및 지방 침투의 가능성을 지적하며 이에 대해 
조기 안정화 운동을 지지하는 선행연구가 있다. 반면에 단점으로는 Paoloni 등 10 의 리뷰논문에서 조기 운동이 수술 이후 1 년 이내의 관절 가동범위의 증진에는 효과적이나 수술 부위의 이른 움직임으로 인 해 재 파열의 위험성이 더 높다고 보고되었다. 이러한 단점으로 인해 수술 이후 재활은 충분한 고정기간 이후에 안정화 운동을 실시하기 를 권장하는 상반되는 연구 ${ }^{11}$ 가 있으나 최근 Keener 등ㄹㅇㅢ 연구에서 는 초기 3 개월에 능동적인 움직임과 바깥돌림에서 유의한 차이를 보 인 조기 운동의 중요성을 강조하기도 하였다. 이처럼 조기 운동을 지 지 하는 연구는 고정기간 동안의 관절가동범위와 관절구축을 염려 하고 지연 운동을 지지 하는 연구는 이른 움직임이 수술 부위의 재 파열을 초래 한다고 지적하고 있다.

재활 프로토콜을 안전하고 개개인에 맞춘 안정화 운동을 제공하 기 위해서는 치유과정에 따른 기간과 생리학적인 부분을 이해하는 것이 중요하다." 돌림근띠 치유과정에는 정형외과 수술 직후인 염증 단계(7일), 증식 단계(2-3주) 및 성숙 또는 재형성 단계(12-26주)의 3단 계가 있다. ${ }^{13}$ 힘줄과 뼈 고정 이후 혈소판 및 섬유 아세포와 함께 염증 세포가 첫 주에 수복 부위로 이동하여 다음 2-3주 동안 증식한다. 이 단계의 세포 증식 및 기질 배열은 몇 가지 성장 인자에 의해 조절되며 수복 후 3-4주가 지나면 재형성 절차가 시작되고 세포 외 기질을 전 환하여 반흔조직을 구성한다.14 초기 3형 콜라겐 형성은 성숙한 반흔 조직이 형성 될 때까지 천천히 콜라겐 1형으로 대체된다. ${ }^{5}$ 해부학적 으로 어깨관절은 어깨뼈와 빗장뼈 그리고 위팔뼈 머리와 관절하는 관절로써 어깨뼈와 그에 부착되어 안정시키는 근육들에 대한 이해 가 필요하다. 어깨뼈의 역할은 기본적으로 근육의 부착부위이고 이 역할은 어깨뼈를 안정시키는 근육이 어깨뼈에 붙어서 주로 관절 또 는 신체 부위의 움직임이나 위치를 제어하는 짝이 되는 근육들의 시 너지 협력수축과 짝힘을 통해 어깨뼈 운동이 조절된다. ${ }^{16}$ 이 짝힘들의 주요 기능은 관절오목과 위팔뼈 두 사이를 최대한 조화롭게 하고 역 학적으로 관절오목의 안정성을 제공하며 최적의 길이와 긴장 관계를 유지하는 것이다. ${ }^{7}$ 이러한 어깨뼈 안정화를 위해 어깨뼈에 부착되는 근육에는 등세모근, 마름근, 앞톱니근, 어깨올림근 그리고 돌림근띠 가 있다. 어깨뼈 안정화를 위한 짝힘은 마름근과 함께 움직이는 위쪽 과 아래쪽등세모근들은 앞톱니근과 짝을 이룬다. 돌림근띠의 근육 은 어깨뼈의 전체 표면을 따라 붙어서 위팔뼈 머리를 소켓에 압착하 여 외전의 $70^{\circ}-100^{\circ}$ 사이에서 가장 효율적인 안정화 활동이 일어나도 록 정렬된다. ${ }^{16}$ 어깨뼈의 역할은 최적의 기능을 위해 가장 적절한 어 깨 위치를 결정할 수 있는 근위-원위의 에너지 전달에서의 연결로 가 장 잘 표현된다. 또한 힘과 에너지의 주요 원천인 다리와 체간의 큰 힘 과 높은 에너지를 실제 전달 구조인 팔과 손으로 옮기는 데 중추적인 역할을 한다. 이러한 동작은 어깨뼈가 안정화 되었을 때 가장 효율적 으로 수행 될 수 있으므로 오목위팔관절과 어깨가슴관절로부터 안
정성을 제공받아야움직일 수 있다

이런 해부생리학적 기전을 통해 돌림근띠 봉합술 직후 오목위팔 관절을 둘러싸고 있는 돌림근띠의 직접적인 움직임을 적용하는 안정 화 운동 프로그램은 돌림근띠 근육의 과도한 긴장 및 수동적 스트레 칭, 근육 활동으로 인해 봉합술의 결과가 실패로 이루어 질 수 있다. 그러므로 조기 운동을 실시 하되 돌림근띠가 지나가는 관절인 오목 위팔관절의 움직임 배제하여 돌림근띠의 부하를 줄이고 어깨뼈에 부착 되어 있는 돌림근띠를 제외한 안정화 근육의 운동을 실시하여 어깨가슴관절의 움직임만으로 6주간의 고정으로 발생될 수 있는 근 육 위축을 방지하고자 한다. 현재까지의 연구가 복원수술 이후 조기 운동과 지연 운동으로 시점에 초점이 맞춰져 있거나 조기 운동 시수 술 이후 적극적인 개입으로 뻗침운동, 돌림근띠 등척성운동, 돌림근 띠 근력강화 등을 단계적으로 시행하여 어깨 안정화에 다양한 방법 과 안정화 운동 프로토콜이 제시되고 있지만 돌림근띠의 부착부위 인 오목위팔관절의 직접적인 움직임이 있는 연구 ${ }^{18}$ 가 이루어져왔다. 하지만 수술 이후 회복에 대한 해부생리학적 기전과 돌림근띠 이외 오목위팔관절의 주변근육 역할이 어깨빼 움직임에 어떠한 영향을 미치는지에 대한 고려가 필요하다고 사료된다. 본 연구는 조기 운동 을 실시 하여 오목위팔관절의 움직임을 제한한 어깨가슴관절을 이 용한 안정화 운동과 기존에 실시되어 왔던 오목위팔관절의 움직임이 포함된 안정화 운동과의 차이를 알아보고자 한다.

\section{연구 방법}

\section{1. 연구대상}

본 연구의 대상자는 $\mathrm{G}$ 시에 위치한 $\mathrm{O}$ 정형외과에서 자기공명영상 상 파열의 깊이가 2-4 cm 미만인 돌림근띠 부분 파열로 진단받아 수술 직후 C한방병원에 내원한 환자들을 대상으로 하였다. 대상자 모집기 간은 2018년 7월 1일 부터 8월 31일까지 본 연구의 목적과 방법을 충분 히 이해하고 연구에 참여하기로 동의한 30 명을 대상으로 하였다.

돌림근띠 부분 파열로 봉합술을 시행한 환자를 대상으로 하였으 며, 선정 된 대상자를 그룹 I은 오목위팔관절(glenohumeral joint) 움직 임을 포함한 어깨관절(shoulder joint, SJ) 안정화 운동군 15명, 그룹 II 는 오목위팔관절 움직임을 제외한 어깨가슴관절(scapulothoracic

Table 1. The general characteristics of subject $(n=30)$

\begin{tabular}{lrccc}
\hline & $\begin{array}{r}\text { Group I } \\
(n=15)\end{array}$ & $\begin{array}{c}\text { Group II } \\
(n=15)\end{array}$ & $t$ & $P$ \\
\hline Age (yr) & $53.7 \pm 9.6$ & $52.7 \pm 9.3$ & 0.308 & 0.760 \\
Height $(\mathrm{cm})$ & $166.4 \pm 7.3$ & $165.0 \pm 8.1$ & 0.495 & 0.624 \\
Weight $(\mathrm{kg})$ & $69.9 \pm 8.4$ & $69.7 \pm 10.4$ & 0.039 & 0.969 \\
\hline
\end{tabular}

All values showed Mean \pm Standard deviation, Group I: shoulder joint stabilization exercise, Group II: scapulothoracic joint stabilization exercise. 
joint, STJ) 안정화 운동군 15 명으로 30 명을 무작위로 선정하였다.

어깨 전방 불안정성을 동반한 환자, 위팔두갈래근 긴머리 절제술 환자 또는 힘줄 고정술이 필요한 환자, 동일한 부위에 수술을 받았던 자, 봉우리빗장관절염 환자, 신경 손상이 있는 환자, 정신장애나 본 연 구에서 실시하는 실험동작을 이해하지 못하는 자는 본 연구에서 제 외 하였다. 중재 전 각 군간의 동질성 검정 결과 모든 항목에서 유의 한차이가 없는 것으로 나타났다 $(\mathrm{p}>0.05)($ Table 1$)$.

\section{2. 실험방법}

1) 중재방법

오목위팔관절의 움직임을 포함한 어깨관절 안정화 운동 그룹 I은 Brotzman과 Manske ${ }^{19}$ 의 저서를 참고하여 본 연구의 목적에 맞게 돌림 근띠 부분 파열에 있어 관절경하 봉합수술 이후 안정화 프로토콜 부 분을 차용, 수정 보완하여 주차별 운동 프로토콜을 제작해 적용하였 다(Table 2). 주차별 운동 프로토콜은 1주차부터 오목위팔관절의 직접 적인 움직임과 환자의 상태에 따라 3 주차부터 오목위팔관절의 저항 운동이 포함되어 있다. 오목위팔관절의 움직임을 배제하여 어깨가슴 관절의 움직임만으로 안정화를 실시한 어깨가슴관절 안정화 운동 그 룹 II는 어깨뼈 패턴 anterior elevation, posterior depression, posterior elevation, anterior depression의 4가지 운동을 사용하여 옆으로 누운 자세 에서 어깨가슴관절의 대각선 운동을 실시하게 하였다(Figure 1).

운동 치료 프로그램은 각 환자의 능력에 맞게 조정하여 통증을 악 화시키지 않으면서 주어진 운동에 대해 10 번 반복을 3 세트 완료하는 환자의 능력에 따라 운동 강도를 조정한다. 모든 운동에 대한 가장 중 요한 원칙은 운동 중에 0 에서 10 까지의 시각적 상사 척도가 5 이상인 통증을 유발하지 않는다. 운동 시 발생되는 통증에 대해 미리 예측

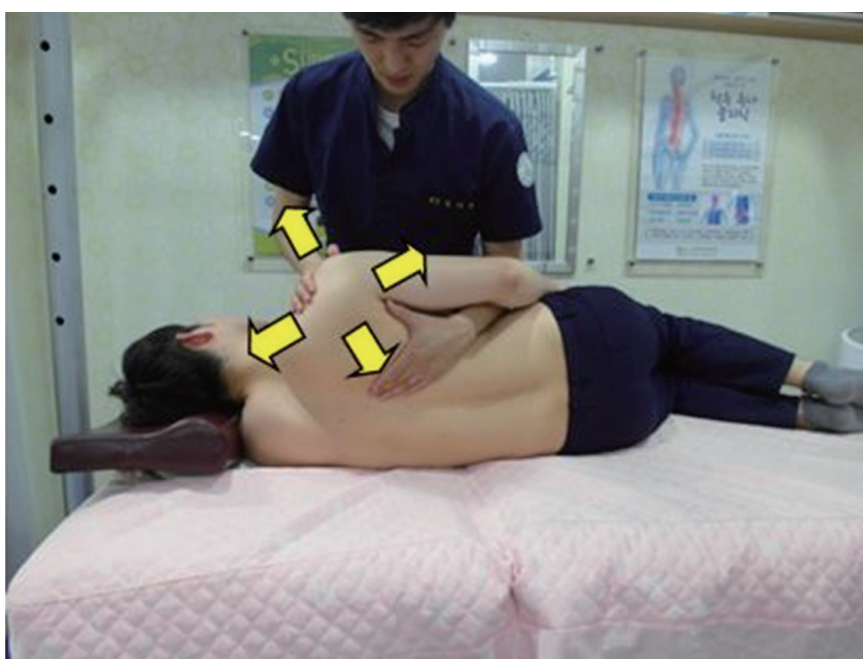

』Direction of active movement 』Direction of resistance movement
할 수 있도록 통증 변화와 대처 방법에 대하여 설명하고 적절하게 운 동할 수 있도록 운동방법에 대하여 이해하기 쉽게 직접시범을 보여 주는 사진을 첨부하여 환자에게 배포하였다. 30 분씩 주 5 회 5 주간 시 행하였다.

종속변인을 측정하기 위해 환자가 스스로 상지의 주관적 상태를 평가 할 수 있는 상지기능 장애(disabilities of the arm, shoulder and hand, DASH) 설문지, 어깨관절 굽힘 시 관절가동범위를 측정하기 위 해 관절각도계(JAMAR Stainless steel goniometer, Preston, USA)를 사 용하였고, 악력계(T.K.K.5401, Takei, Japan)를 사용하여 돌림근띠의 근 활성도를 수집하였다.

Table 2. Weekly exercise program

\begin{tabular}{|c|c|}
\hline & Exercise method \\
\hline 1-2 weeks protocol & $\begin{array}{l}\text {-Pain control (Ice pack) } \\
\text {-Massage the muscle around neck and chest } \\
\text {-Elbow joint flexion and extension } \\
\text {-Glenohumeral joint flexion and extension } \\
\text { (Full assist, Up to } 110 \text { degrees or less) }\end{array}$ \\
\hline 3 weeks protocol & $\begin{array}{l}\text {-Scapular joint mobilization } \\
\text {-Scapular joint Assisted-active exercise } \\
\text {-External rotation exercise } \\
\text { (less than } 30 \text { degrees from scapular border) }\end{array}$ \\
\hline 4-5 weeks protocol & $\begin{array}{l}\text {-Abduction ROM exercise in supine position (pain free) } \\
\text {-Abduction isometric exercise in supine position } \\
\text {-Glenohumeral joint assisted-active stabilization } \\
\text { exercise in supine position } \\
\text {-External rotation isometric exercise in supine position } \\
\text {-Glenohumeral joint flexion and extension isometric } \\
\text { exercise in standing position }\end{array}$ \\
\hline 6 weeks protocol & $\begin{array}{l}\text {-Glenohumeral joint mobilization at the end range } \\
\text {-Shoulder flexion exercise using cane or assistive device } \\
\text {-Abduction exercise more than } 90 \text { degrees in supine } \\
\text { position } \\
\text {-Backward exercise using Theraband }\end{array}$ \\
\hline
\end{tabular}

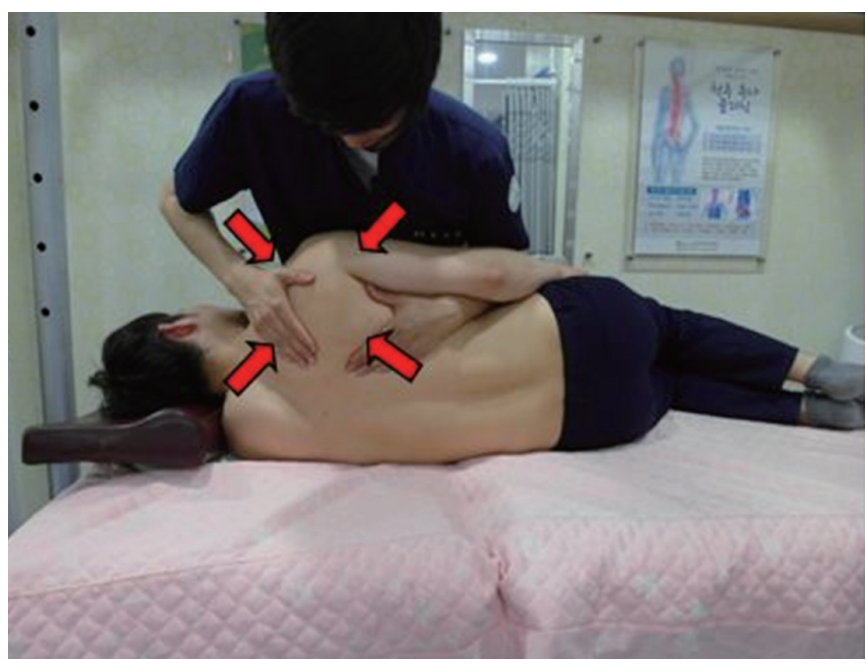

Figure 1. Scapular pattern exercise. 


\section{2) 측정도구}

\section{(1)상지기능 장애 평가 설문지}

상지기능 장애(disabilities of the arm, shoulder and hand, DASH) 평가 설문지는 동작수행능력 평가의 30 문항으로 구성되어 있고 5점 서열 척도로 100 점 만점으로 환산하여 점수가 높을수록 더욱 심한 장애 가 있음을 나타낸다. 설문도구에 대한 높은 타당도와 신뢰도가 널리 알려져 있으며 한국어판 DASH 설문지의 Cronbach's $\alpha$ 는 0.94 였다. ${ }^{20}$

$\mathrm{DASH}$ 설문지는 증상 및 특정한 동작을 수행하는 능력에 관한 질 문으로 구성되어 지난 주 상태를 기준으로 답변하며 만약 지난 주 동 안 질문한 동작을 할 기회가 없었다면 상태에 가장 가까운 답변하고 봉합수술을 실시한 환측에 대한 수행능력을 기준으로 답변하도록 하였다.

\section{(2)관절가동범위 평가}

어깨관절 관절가동범위 측정은 신뢰도와 타당도가 검증된 관절각도 계(JAMAR Stainless steel goniometer, Preston, USA)를 이용하였다. 환 자는 똑바로 서고 팔은 옆으로 놓은 자세에서 시작하여 축은 어깨뼈 봉우리의 부리돌기에 놓고 고정자는 겨드랑이의 중앙선에 이동자는 위팔뼈의 중심선에 일치하여 어깨관절 굽힘을 측정한다. 이는 수술 후 4-6주간은 어깨관절의 폄, 모음 및 안쪽돌림이 봉합부에 과도한 장력이 가해짐으로써 힘줄과 뼈 사이에 간격형성을 일으키고, ${ }^{21}$ 벌림 과 가쪽돌림은 봉합부의 수축이 이루어지므로 본 연구에서의 관절 가동범위는 수술 이후 초기부터 측정이 실시되어 어깨관절 굽힘만 을 측정하였다. 관절가동범위 평가는 관절면의 구축과 근육 위축의 차이가 있을 수 있어 수동적 관절가동범위와 능동적 관절가동범위 를 평가하였다. 동통이 있거나 제한이 되는 지점에서 동작을 멈추도 록 하여 굽힘 관절가동범위를 3 번 측정 후 평균값을 사용하였다.

\section{(3)악력 평가}

손의 악력 수준을 평가하기 위해 악력계(T.K.K. 5401, Takei, Japan)를 사용하였고 검사-재검사 간에 상관계수는 .99로 높은 신뢰도를 가진 다. 악력은 세모근과 돌림근띠의 힘을 재분배 하는데 관여하여 근 활 성도에 영향을 주며, ${ }^{22}$ 악력이 높아질수록 돌림근띠의 높은 근 활성 도를 보인 Jang 등 23 의 선행연구를 토대로 악력을 평가하였다. 악력 수준의 평가법은 환자가 앉은 상태에서 어깨관절은 모음, 팔꿉관절 은 $90^{\circ}$ 굽힘한 자세에서 손목관절은 $30^{\circ}$ 펴고 $15^{\circ}$ 자측 편위시킨 자세 에서 최대 힘을 주도록 하여 악력을 측정하였다. 악력수준 평가는 각 측정 간에 30 초의 휴식기를 가지고 총 3 회 실시하여 측정한 값들의 평균값을 측정치로 결정하였다.

\section{3) 자료처리}

연구 대상자의 일반적 특성은 기술통계를 사용해 평균과 표준편차 로 제시하였다. 수집된 자료들의 정규성을 검증하기 위해 샤피로-윌 크(Shapiro-Wilk) 분석을 실시하여 모든 자료의 정규분포를 확인하였 다. 그룹 I과 그룹 II에서 각각 중재 전과 후에 상지기능 장애 평가, 관 절가동범위 평가, 악력 평가를 비교하기 위하여 대응표본 t-검정을 실 시하였다. 또한 두 군 간에 측정 변수들의 수준과 중재 전후의 평균 값을 비교하기 위하여 독립표본 t-검정을 실시하였다. 통계처리는 window version SPSS program 21.0 (SPSS Inc., Chicago)을 이용하였으 며 모든 통계학적 유의수준은 $\alpha=0.05$ 로 설정하였다.

\section{결 과}

\section{1. 상지기능 장애 평가}

1) 중재 전후 상지기능 장애 수준 평가 비교

그룹 간 평균 변화를 비교하기 위해 사전 측정값에서 사후 측정값을 뺀 차이 값을 표기하였다. 중재 전후에 따른 그룹 I, 그룹 II의 상지기 능 장애 평가는 그룹 모두 중재 전에 비해 중재 후에 통계학적으로 유 의하게 감소하였다 $(\mathrm{p}<0.05)$

중재 전후 상지기능 장애 수준 평가의 변화량 차이 검정에서 그룹 간 중재 전후 상지기능 장애 수준 평가의 변화량 차이는 통계학적으 로 유의한차이가 없었다( $\mathrm{p}>0.05)$ (Table 3$)$.

\section{2. 관절가동범위 평가}

\section{1) 중재 전후 수동적 관절가동범위 평가 비교}

그룹 간 평균 변화를 비교하기 위해 사전 측정값에서 사후 측정값을 뺀 차이값을 표기하였다. 중재 전후에 따른 그룹 I, 그룹 II의 수동적 관절가동범위 평가는 그룹 모두 중재 전에 비해 중재 후에 통계학적 으로 유의하게 증가하였다 $(\mathrm{p}<0.05)$.

중재 전후 수동적 관절가동범위 평가의 변화량 차이 검정에서 그 룹 간 중재 전후 수동적 관절가동범위 평가의 변화량 차이는 통계학 적으로 유의한 차이가 없었다( $\mathrm{p}>0.05)$ (Table 3$)$.

\section{2) 중재 전후 능동적 관절가동범위 평가 비교}

그룹 간 평균 변화를 비교하기 위해 사전 측정값에서 사후 측정값을 뺀 차이 값을 표기하였다. 중재 전후에 따른 그룹 I, 그룹 II의 능동적 관절가동범위 평가는 그룹 모두 중재 전에 비해 중재 후에 통계학적 으로 유의하게 증가하였다 $(\mathrm{p}<0.05)$.

중재 전후 능동적 관절가동범위 평가의 변화량 차이 검정에서 그 룹 간 중재 전후 능동적 관절가동범위 평가의 변화량 차이는 통계학 적으로 유의한차이가 없었다 $(\mathrm{p}>0.05)$ (Table 3$)$. 
Table 3. Comparison of outcome measures among groups at pre-post intervention

\begin{tabular}{|c|c|c|c|c|}
\hline & $\begin{array}{l}\text { Group I } \\
(n=15)\end{array}$ & $\begin{array}{c}\text { Group II } \\
(n=15)\end{array}$ & \multirow[t]{2}{*}{$\mathrm{t}$} & \multirow[t]{2}{*}{$p$} \\
\hline & \multicolumn{2}{|c|}{ Mean $\pm S D$} & & \\
\hline \multicolumn{5}{|c|}{ DASH (point) } \\
\hline Pre test & $84.88 \pm 5.40$ & $86.48 \pm 5.80$ & & \\
\hline Post test & $63.15 \pm 9.80$ & $62.04 \pm 8.85$ & & \\
\hline Pre-Post & $-21.73 \pm 7.39$ & $-24.44 \pm 11.84$ & 0.752 & 0.459 \\
\hline $\mathrm{t}$ & -11.378 & -7.990 & & \\
\hline $\mathrm{p}$ & $0.000^{*}$ & $0.000^{*}$ & & \\
\hline \multicolumn{5}{|c|}{ Passive ROM $\left({ }^{\circ}\right.$ ) } \\
\hline Pre test & $155.33 \pm 18.46$ & $150.66 \pm 22.18$ & & \\
\hline Post test & $164.00 \pm 11.37$ & $166.66 \pm 6.98$ & & \\
\hline Pre-Post & $8.66 \pm 9.15$ & $16.00 \pm 17.84$ & -1.416 & 0.168 \\
\hline $\mathrm{t}$ & 3.666 & 3.742 & & \\
\hline$P$ & $0.003^{*}$ & $0.004^{*}$ & & \\
\hline \multicolumn{5}{|c|}{ Active ROM $\left({ }^{\circ}\right)$} \\
\hline Pre test & $44.00 \pm 14.73$ & $46.53 \pm 12.39$ & & \\
\hline Post test & $77.60 \pm 21.72$ & $66.26 \pm 17.69$ & & \\
\hline Pre-Post & $33.60 \pm 24.01$ & $19.73 \pm 21.55$ & 1.664 & 0.107 \\
\hline $\mathrm{t}$ & 5.420 & 3.546 & & \\
\hline $\mathrm{p}$ & $0.000^{*}$ & $0.003^{*}$ & & \\
\hline \multicolumn{5}{|c|}{ Grip power (kg) } \\
\hline Pre test & $6.74 \pm 1.29$ & $6.15 \pm 0.60$ & & \\
\hline Post test & $19.62 \pm 3.59$ & $18.16 \pm 2.76$ & & \\
\hline Pre-Post & $12.88 \pm 3.72$ & $12.00 \pm 3.00$ & 0.712 & 0.482 \\
\hline $\mathrm{t}$ & 13.392 & 15.489 & & \\
\hline $\mathrm{p}$ & $0.000^{*}$ & $0.000^{\star}$ & & \\
\hline
\end{tabular}

All values showed Mean \pm Standard deviation, Group l: shoulder joint stabilization exercise, Group II: scapulothoracic joint stabilization exercise. ${ }^{*} p<0.05$.

\section{3. 악력 평가}

1) 중재 전후 악력 평가

그룹 간 평균 변화를 비교하기 위해 사전 측정값에서 사후 측정값을 뺀 차이값을 표기하였다. 중재 전후에 따른 그룹 I, 그룹 II의 악력 평 가는 그룹 모두 중재 전에 비해 중재 후에 통계학적으로 유의하게 증 가하였다 $(\mathrm{p}<0.05)$.

중재 전후 악력 평가의 변화량 차이 검정에서 그룹 간 중재 전후 악 력 평가의 변화량 차이는 통계학적으로 유의한 차이가 없었다(p> 0.05)(Table 3).

\section{고 찰}

성공적인 수술 후에도 통증, 근육의 경직, 근력 및 가동성 저하는 환 자에게 활동능력의 장애를 가져와 수술 이후 회복 및 정상 생활로의 복귀에 지장을 초래하는데 이를 완화시키기 위해서는 안정화 운동 치료가 필요하다. 어깨관절은 인체에서 가장 가동성이 큰 관절로 관
절 주변의 여러 기능적 구조물에 의해 가동성과 안정성이 유지되 며, ${ }^{24-26}$ 특히 어깨복합체 안정근들의 협력수축에 의해 정상적이고 기 능적인 움직임이 가능하게 된다.2728 이러한 돌림근띠 수술 이후 지연 안정화 운동은 수술 후 6 주까지 봉합부위의 보호 및 유지, 점진적인 수동 관절운동범위의 증진, 통증과 염증 조절, 독립적인 일상생활동 작 수행에 대한 적응 등을 치료목표로 한다.10 하지만 여전히 돌림근 띠 수술 이후 재활치료 초기단계에서 봉합조직의 조기 안정화 운동 과 수술 후 6 주간 고정을 기본으로 하는 지연 안정화 운동 중 어느 쪽 이 어깨관절 기능 회복에 더 좋은가에 대한 논란이 있으며 아직 확실 하게 밝혀지지 않았다. 이에 본 연구는 어깨관절의 기능적인 회복과 일상생활동작 수행에 대한 회복을 위해 조기 안정화 운동군인 그룹 I과 수술 부위인 오목위팔관절의 직접적인 움직임을 제외하여 어깨 복합체의 전체적인 안정성 확보를 통한 안정화 운동군인 그룹 II의 어 깨 안정화 효과차이를 알아보고자 실시하였다.

본 연구에서 중재 전후에 따른 상지기능 장애 수준 평가는 통계학 적으로 유의하게 감소하였다 $(\mathrm{p}<0.05)$. 돌림근띠의 파열이 발생한 환 자에게 통증 및 어깨관절의 근력약화는 상지의 기능장애를 일으키 는 원인이 되고 어깨관절 주위근의 보상작용이 일어나는 것이 일반 적인데, 이와 같은 보상작용은 오목위팔관절의 움직임에 대한 어깨 가슴관절의 위쪽돌림으로 이루어지는 것이 일반적이다. ${ }^{29}$ 이와 같은 결과는 두 군 모두 적용된 어깨 안정화 운동이 과도한 위쪽등세모근 의 작용을 억제시키고 앞톱니근의 작용을 강화시켜 앞톱니근과 짝 을 이루는 위쪽과 아래쪽등세모근들의 적절한 작용으로 어깨뼈의 위쪽돌림이 원활하게 이루어지도록 도와준 것이라 생각되며, 결과적 으로 상지기능장애 수준 평가를 낮추는데 긍정적인영향을 미친다 는 것으로 생각된다.

관절가동범위 평가에서는 중재 전후에 따른 수동적 관절가동범 위 평가는 그룹 모두 중재 전에 비해 중재 후에 통계학적으로 유의하 게 증가하였다 $(\mathrm{p}<0.05)$. 선행연구 ${ }^{30}$ 에서 염려하는 고정화에 따른 유 착 및 관절가동범위 감소는 수술 이후 중재기간까지 총 6 주 동안 수 동적 관절가동범위의 유의한 증가로 유착과 관절가동범위 감소는 보 이지 않았다. 중재 전후에 따른 능동적 관절가동범위 평가는 그룹 모 두 중재 전에 비해 중재 후에 통계학적으로 유의하게 증가하였다 $(\mathrm{p}<0.05)$. 어깨의 굽힘은 순간적으로 돌림근띠의 기능에 의해 안정성 을 확보하여 세모근들의 힘과 넓은등근, 큰가슴근, 큰원근의 팔을 아 래로 누르는 힘에 의해서 팔을 위로 올리는 큰 움직임을 할 수 있 다. ${ }^{31,32}$ 두 군 모두 어깨 안정화 근육들의 훈련을 통해 대상적인 움직 임을 줄이고 가동화 단계에서 나타나는 불균형을 정상적으로 되돌 리는 결과는 선행연구 33 와 일치함을 볼수 있다.

Jang 등23은 쥐기와 연관된 어깨 근 활성도 변화를 통해 어깨 손상 기전을 유추하는데 사용될 수 있을 것이라고 하였고, 쥐기 동작은 여 
러 직업 활동과 스포츠 활동에서 운동생리학적으로 흔하게 수행되 며 상지근육의 활성도를 변화시킬 수 있다고 보고되고 있다. ${ }^{34}$ 이에 중재 전후에 따른 악력 평가는 그룹 모두 중재 전에 비해 중재 후에 통계학적으로 유의하게 증가하였다 $(\mathrm{p}<0.05)$. 근육 위축은 근육을 지 배하는 신경의 손상이나 장기간 사용하지 않은 상태에서 근섬유의 감소와 근력이 감소되는 현상을 말하며, ${ }^{35}$ 그룹 I은 직접적인 오목위 팔관절의 움직임을 시행하는 돌림근띠의 훈련을 통해 강화되었음을 유추할 수 있다. 또한 근육 활동의 효율성은 어깨뼈의 가슴우리에 대 한 최적 정렬과 어깨뼈 안정화와 돌림근띠의 길이-긴장 관계에 달려 있고 어깨관절의 동적 안정성을 제공하기 위해서는 오목위팔관절과 어깨가슴관절의 협조적인 활동이 필수적이다. ${ }^{36}$ 그룹 II도 수술 직후 직접적인 오목위팔관절의 움직임이 없더라도 어깨가슴관절의 안정 화 운동을 통해 근육 활동의 효율성을 높여 근 활성도가 높음을 알 수 있다. 이는 앞톱니근이 약화되면 어깨뼈의 회전을 방해하여 어깨 위팔리듬을 저해하는 원인이 된다고 하였으며 이러한 비정상적 움직 임을 해결하기 위해 앞톱니근의 강화를 제안한 선행연구 ${ }^{37}$ 와 의견이 일치한다. 힘줄 조직의 대사 회전율은 근육보다 느리므로 최적의 힘 줄 치유를 달성하기 위해서는 힘줄의 부하를 조절하고 점진적으로 증가시키는 것이 중요하다. ${ }^{38}$ 이는 수술 직후 조기 운동에 따른 이른 시기에 시작하는 부드러운 관절운동은 힘줄의 치료를 돕는다. ${ }^{39}$ 또한 치유의 증식 단계에서 안정화 운동을 시작하고 개조 단계로 계속 진 행하여 콜라겐이 힘줄의 형성과 최종 강도에 도움이 되는 하중을 받 게 되고 이것은 수술 이후 고정이 힘줄강도를 감소시킬 수 있으며 재 파열의 위험을 증가시킬 수 있음을 의미한다. ${ }^{40}$ 돌림근띠의 수술 이후 근육 위축이 보이지 않고 수술 직후와 중재 이후 근 두께 변화가 없 음이 시사하는 바는 돌림근띠의 회복이 진행되는 것을 의미한다.

본 연구의 결과에서 오목위팔관절 움직임을 포함한 어깨관절 안 정화 운동군, 오목위팔관절 움직임을 제외한 어깨가슴관절 안정화 운동군 모두 수술 이후 조기에 적용 하였을 시 효과적이었고 두 군간 의 효과가 유의한 차이는 없었다. 두 군간의 차이가 없는 결과로 보아 어깨뼈 주변 근육이 안정화 되었을 때 오목위팔관절이 어깨가슴관 절로부터 안정성을 제공받아야 가장 효율적으로 수행 될 수 있다는 점을 시사한다. 연구의 제한점으로는 대상자의 숫자가 많지 않고 한 지역의 병원에 내원한 환자들을 대상으로 하였기에 연구 결과를 일 반화하기에는 한계가 있다. 또한 돌림근띠 파열의 크기를 범위로 지 정한 것과 추적조사를 통한 재 파열의 위험성 확인도 선행연구의 결 과를 통하여 추정하였다는 점이다. 그러나 연구 결과를 통해서 안정 화 운동 시 오목위팔관절의 움직임 없이 어깨가슴관절 근육의 강화 운동이 수술 부위의 직접적인 관절움직임이 없는 운동임에도 충분 히 안정성을 확보할 수 있다는 점을 보여준다. 어깨관절의 움직임은 돌림근띠의 활성만으로는 움직이지는 것이 아니고 어깨 복합체의 안
정성이 확보되어야 유기적인 움직임을 보일 수 있다는 점을 유추 할 수 있었고, 따라서 수술 이후 장기간의 고정은 어깨 복합체의 약화를 초래할 수 있다는 우려가 있기 때문에 '조기 운동'이 선행되어야함은 맞으나 해부생리학적 근거에 따라 수술 부위의 직접적인 움직임을 지양하는 운동법도 충분히 효과적임을 입증하고자 하였다. 본 연구 는 안정화 운동 시작시기에 관한 많은 최근 연구들과 달리, 초기 관절 가동범위 확보라는 '조기 운동'의 이점을 살리면서 수술 부위의 직접 적인 운동으로 인한 추후 재 파열의 위험성을 재기 하는 '조기 운동' 을 반대하는 선행연구들의 우려를 해소해 보고자 제시하였으며 앞 으로 이에 대한 더 많은 연구가 필요할 것이라 생각된다.

\section{REFERENCES}

1. Jeon CB, Choi SJ, Oh HJ et al. The effects of high intensity laser therapy on pain and function of patients with frozen shoulder. J Kor Phys Ther. 2017;29(4):207-10.

2. Luime JJ, Koes BW, Hendriksen IJ et al. Prevalence and incidence of shoulder pain in the general population; a systematic review. Scand J Rheumatol. 2004;33(2):73-81.

3. Kim JW, Kim YN. Effect of sling exercise on muscle activity and pain in patients with rotator cuff repair. J Kor Phys Ther. 2017;29(2):45-9.

4. Minagawa H, Yamamoto N, Abe $\mathrm{H}$ et al. Prevalence of symptomatic and asymptomatic rotator cuff tears in the general population: from massscreening in one village. J Orthop. 2013;10(1):8-12.

5. Wirth MA, Basamania C, Rockwood Jr CA. Prevalence of symptomatic and asymptomatic rotator cuff tears in the general population: from mass-screening in one village Orthopedic Clinics of North America. 1997;28(1):59-67.

6. Yoo YS, Noh KC, Kim IS et al. Efficacy of direct arthroscopy-guided suprascapular nerve block after arthroscopic rotator cuff repair: A prospective randomized study. Knee Surg Sports Traumatol Arthrosc. 2015;23(2):562-6.

7. Lee IS. Rehabilitation after shoulder surgery. J Korean Med Assoc. 2014;57(8):679-84.

8. Saltzman BM, Zuke WA, Go B et al. Does early motion lead to a higher failure rate or better outcomes after arthroscopic rotator cuff repair? A systematic review of overlapping meta-analyses. J Shoulder Elbow Surg. 2017;26(9):1681-91.

9. Van Der Meijden OA, Westgard P, Chandler Z et al. Rehabilitation after arthroscopic rotator cuff repair: current concepts review and evidencebased guidelines. In J Sports Phys Ther. 2012;7(2):197.

10. Paloni M, Bernetti A, Santilli V et al. Rehabilitation after rotator cuff repair in rotator cuff tear, Springer, Cham, 2017:369-80.

11. Millett PJ, Wilcox lll RB, O'holleran JD et al. Rehabilitation of the rotator cuff: and evaluation-based approacj. J Am Acad Orthop Surg. 2006; 14(11):599-609.

12. Keener JD, Galatz LM, Stobbs-Cucchi G et al. Rehabilitation following arthroscopic rotator cuff repair: a prospective randomized trail of immobilizaion compared with early motion. JBJS. 2014;96(1):11-9.

13. Gulotta LV, Rodeo SA. Growth factors for rotator cuff repair. Clin Sports 
Med. 2009;28(1):13-23.

14. Carpenter JE, Thomopoulos S, Flanagan CL et al. Rotator cuff defect healing: a biomechanical and histologic analysis in an animal model. J Shoulder Elbow Surg. 1998;7(6):599-605.

15. Lewis CW, Schlegel TF, Hawkins RJ et al. The effect of immobilization on rotator cuff healing using modified Mason-Allen stitches: a biomechanical study in sheep. Biomed Sci Instrum. 2001;263-8.

16. Ben Kibler W. The role of the scapula in athletic shoulder function. Am J Sports Med. 1998;26(2):325-37.

17. Kamkar A, Irrgang JJ, Whitney SL. Nonoperative management of secondary shoulder impingement syndrome. J Orthop Sports Phys Ther. 1993;17(5):212-24.

18. Bang H, Lee H. Effect of early muscle strengthening exercise on pain, function and sleep quality for rotator cuff partial tear patients. KSIM, 2014;2(4):69-81.

19. Brotzman B, Manske R. Clinical orthopaedic rehabilitation elsevier health sciences. New York, Expert Consult, 2012.

20. Lim JY, Lee HY, Song JH et al. Evaluation of the reliability, construct validity, and responsiveness of the korean version of the DASH. J Korean Soc Surg Hand. 2005;10(4):192-8.

21. Chung MS, Gong HS, Kim SH et al. The shoulder surgery. Seoul, Koonja, 2010.

22. Zakaria D. Rates of carpal tunnel syndrome, epicondylitis, and rotator cuff claims in Ontario workers during 1997. Chronic Dis Can. 2004; 46(54.86):74-52.

23. Jang HJ, Kim JS, Choi JD et al. The effects of hand grip force on shoulder muscle activity in two arm posture. KJTE. 2012;13(3):1229-37.

24. Veeger HEJ, Van Der Helm FCT. Shoulder function: the perfect compromise between mobility and stability. J Biomech. 2007;40(10):211929.

25. Jeong JG, Park JC. The impact of vibration exercises on shoulder muscle thickness. J Kor Phys Ther. 2018;30(4):117-22.

26. Kim TH, Kim SY, Park HK. Effect of shoulder protraction exercise on the supine position for selective activation of the serratus anterior according to weight in winging scapula. J Kor Phys Ther. 2019;31(4):199203.

27. David G, Magarey ME, Jones MA et al. EMG and strength correlates of selected shoulder muscles during rotations of the glenohumeral joint. Clin Biomech. 2000;15(2):95-102.

28. Yang SR, Kim YM, Park SJ et al. Efficacy of lumbar segmental stabiliza- tion exercises and breathing exercises on segmental stabilization in lumbar instability patients. J Kor Phys Ther. 2017;29(5):234-40.

29. Jun AY, Yoo YS, Choi EH et al. Clinical Article: The changes of shoulder muscle activities by angular velocities of isokinetic abduction in fullthickness rotator cuff tears. Korean J Sports Med. 2009;27(2):144-9.

30. Lastayo PC, Wright T, Jaffe R et al. Continuous passive motion after repair of the rotator cuff. A prospective outcome study. JBJS. 1998;80(7): 1002-11.

31. Kuechle DK, Newman SR, Itoi E et al. Shoulder muscle moment arms during horizontal flexion and elevation. J Shoulder Elbow Surg. 1997; 6(5):429-39.

32. Jung MY, Ryu YU. Effects of a trunk stabilization exercise with gym ball on scapular position for patients with arthroscopic rotator cuff repair. J Kor Phys Ther. 2018;30(1):8-13.

33. Cuff DJ, Pupello DR. Prospective randomized study of arthroscopic rotator cuff repair using an early versus delayed postoperative physical therapy protocol. J Shoulder Elbow Surg. 2012;21(11):1450-5.

34. Alizadehkhaiyat O, Fisher AC, Kemp GJ et al. Shoulder muscle activation and fatigue during a controlled forceful hand grip task. J Electromyogr Kinesiol. 2011;21(3):478-82.

35. Sayer AA, Robinson SM, Patel HP et al. New horizons in the pathogenesis, diagnosis and management of sarcopenia. Age Ageing. 2013;42(2): 145-50.

36. Culham E, Peat M. Functional anatomy of the shoulder complex. J Orthop Sports Phys Ther 1993;18(1):342-50.

37. McMahon PJ, Jobe FW, Pink MM et al. Comparative electromyographic analysis of shoulder muscles during planar motions: anterior glenohumeral instability versus normal. J Shoulder Elbow Surg 1996;5(2):11823.

38. Thomopoulos S, Williams GR, Soslowsky LJ. Tendon to bone healing: differences in biomechanical, structural, and compositional properties due to a range of activity levels. J Biomech Eng. 2003;125(1):106-13.

39. Lee BG, Cho NS, Rhee YG. Effect of two rehabilitation protocols on range of motion and healing rates after arthroscopic rotator cuff repair: aggressive versus limited early passive exercises. Arthroscopy. 2012; 28(1):34-42.

40. Park MC, Jun BJ, Park CJ et al. The biomechanical effects of dynamic external rotation on rotator cuff repair compared to testing with the humerus fixed. Am J Sports Med. 2007;35(11):1931-9. 